Georgia State University

ScholarWorks @ Georgia State University

2016

\title{
Learning from the Offenders' Perspective on Crime Prevention
}

Scott Jacques

Georgia State University

Elizabeth Bonomo

Northern Arizona University

Follow this and additional works at: https://scholarworks.gsu.edu/ebcs_articles

Part of the Criminology and Criminal Justice Commons, Defense and Security Studies Commons, and the Information Security Commons

\section{Recommended Citation}

Jacques, Scott, and Elizabeth Bonomo. 2016. Learning from the Offenders' Perspective on Crime Prevention. Chapter 2 in Crime Prevention in the 21st Century, eds. Benoit Leclerc and Ernesto U. Savona. New York: Springer.

This Book Chapter is brought to you for free and open access by the Evidence-Based Cybersecurity Research Group at ScholarWorks @ Georgia State University. It has been accepted for inclusion in EBCS Articles by an authorized administrator of ScholarWorks @ Georgia State University. For more information, please contact scholarworks@gsu.edu. 
To learn about crime, including how to prevent it, criminologists should go to the source. As a collective, criminals are the preeminent source of knowledge on crime. ${ }^{1}$ They have a firsthand perspective on what motivates the decision to break the law, obey it, or abort an inprogress offense. Moreover, offenders are experts on the technical process involved in committing crime, such as how to steal a vehicle or rob a pedestrian. And while police and victimization statistics, among other kinds, are indicative of the crime rate, only the collective knowledge of offenders can truly tell us how much crime is committed.

In some sense, offenders are not only the "problem" under study but also the spring from which an answer will be found. This notion serves as part of the basis for "offender-based research," or "OBR" for short. Broadly defined, OBR refers to scholarly work that entails analyzing data collected directly from criminals (Bernasco, 2010). Examples include everything from the survey of students used by Hirschi (1969) in Causes of Delinquency, to experiments involving offenders (e.g., Decker, Wright, \& Logie, 1993), to ethnographies such as Shaw's The Jack-Roller (1930) and Sutherland's (1937) The Professional Thief.

Because offenders are uniquely situated to inform criminology, the potential of OBR for improving crime prevention is enormous. In this chapter, we outline five ways that OBR can be used to inform understanding of crime prevention, more specifically situational crime prevention or "SCP." Each of the lessons is illustrated with an example from the OBR literature. We conclude by discussing the choices involved in conducting OBR for the betterment of SCP.

\footnotetext{
${ }^{1}$ Of course, few if any individuals fill a single criminological role. In one situation, for example, a person may act as an offender, but in another situation be a victim or guardian. Yet for the sake of simplicity, in this paper we refer to one role at a time.
} 


\section{Situational Crime Prevention}

The theoretical premise of SCP is that crime may be prevented by reducing the characteristics of situations that facilitate offending (Clarke, 2009). The practical purpose, then, of SCP is to provide a theoretical framework for deducing ways to block crime opportunities by manipulating the specific situational characteristics that generate them (Clarke, 2009). To do so, SCP draws on the rational choice and routine activity perspectives (Clarke \& Cornish, 1985; Cohen \& Felson, 1979).

The rational choice perspective suggests that an individual's decision on how to act is guided by bounded assessments of potential benefit and cost (Bentham, 1988 [1789]). According to this perspective, an individual is more likely to commit an offense when the perceived benefit of doing so is greater or the perceived risk of incurring cost is smaller (Clarke \& Cornish, 1985). Also, a person is more likely to commit an offense when its perceived utility-i.e., benefits minus costs - is greater than the utility of obeying the law. Examples of benefits include money, status, and pride; examples of costs include fines, diminished respectability, and shame.

Key to the rational choice perspective is that the decision to offend takes place within a concrete situation, defined as a particular time and place. This is crucial because situations vary in the opportunities they hold for crime (Cohen \& Felson, 1979). One aspect of opportunity is the potential benefit and cost associated with a particular situation. For instance, the opportunity for robbery is greater when there is a potential victim with a lot of rather than no cash in possession. And typically, the opportunity for crime is smaller when a police officer is nearby instead of out of sight. The second aspect of opportunity is whether the situation presents the minimal elements involved in committing an offense. For example, a motivated offender cannot rob someone if no one is around to victimize, and a drug distributor cannot sell his or her product if alone on a 
deserted island. While such limitations may seem so obvious as to not even warrant mentioning, their obviousness shows that opportunity is a crucial component in offending.

Returning to SCP, this framework is based on the notion that a person is less likely to commit a crime when there is less opportunity, meaning the crime's potential benefit is smaller, risk is greater, or the minimal elements to do so are absent. SCP is more than an academic pursuit, however, as its purpose is to guide real-life crime prevention efforts. On that note, SCP practices may be categorized as "strategies" or "techniques." SCP "strategies" are broad, or abstract, notions of how to introduce discrete managerial and environmental change that helps reduce crime opportunities (Clarke, 2009). The five strategies of SCP are (1) increasing the effort and (2) risk involved in lawbreaking and (3) reducing the reward, (4) excuse, and (5) provocation to do so (Clarke, 2009). SCP "techniques," on the other hand, are specific procedures based on a given strategy. Examples of the five strategies listed above are, respectively, target hardening, introducing burglars alarms, disrupting markets, curtailing disputes, and displaying signs that specify the law (for further examples, see Clarke, 2009).

\section{Five Ways to Learn from OBR about SCP}

OBR's distinguishing feature is analyzing data collected directly from offenders. The motivation for this research procedure is the assumption that offenders are uniquely situated to inform criminology. Criminals have personal knowledge of how often they commit crime; what motivates offenses; and how they are committed. Moreover, offenders know how often their crimes are prevented; what thwarts offenses; and how so. And therefore, OBR can contribute to knowledge about SCP. There are at least five ways to learn from OBR about SCP. 
Perhaps the most obvious way is to conduct experiments on, make observations of, or ask questions of offenders that directly speak to the effectiveness of a particular SCP technique. An example of the first lesson is provided by Leclerc, Wortley, and Smallbone (2011). They drew on data collected from a sample of adult offenders who sexually abused children to examine the efficacy of potential victims' self-protection techniques. The respondents reported that the most productive way for children to prevent sexual contact was to tell the offender that such contact was not wanted or to say "no," which are examples of reducing the "excuse" to commit a crime - namely that the victim was an active participant. According to the offenders, more than half of the victims successfully avoided sexual contact by employing these techniques. The participants also reported that fighting back and yelling for help were the least effective methods of resisting a sex offender. Though these two techniques are meant to deter offenses by increasing the required effort and risk, the participants stated that these techniques were only successful at warding off an offense in $11.8 \%$ and $4 \%$ of cases, respectively. As the authors note, the implication of these findings is that assertiveness training may be the most valuable intervention point for reducing sex offenses against minors.

A second way to learn about SCP from OBR is by making inferences about what kind of SCP techniques to invent and employ based on criminals' descriptions of their motives and methods of offending. Copes and Cherbonneau (2006), for instance, examined the methods used by auto thieves to steal keys that unlocked the door to vehicles they targeted. While the researchers did not directly examine any particular SCP technique, they drew on their findings to craft suggestions for how to reduce this crime. One finding and concomitant implication is that because offenders are able to steal keys to vehicles, owners should not treat mechanical vehicle security measures (e.g., a car alarm) — which are meant to increase the risk or effort of 
offending — as sufficient to protect against theft. Additionally, owners should take strides to protect their keys. Of course, leaving keys out in the open is a bad idea, but it is also important to recognize that some hiding places are better than others. As the authors note, "spare keys are better protected in the home, no matter how well they are hidden within the vehicle ... [and] it is safer to hide valuables, including spare car keys, in places away from common searching areas. These safer areas include basements, utility rooms, guest rooms and children's bedrooms" (Copes \& Cherbonneau, 2006, p. 930). In the language of SCP, what Copes and Cherbonneau propose is that auto theft can be prevented by increasing the effort involved in obtaining keys. Third, OBR can be used to inform SCP by using qualitative findings to refine what is learned from quantitative analyses. An example relates to Weisburd and colleagues' (2006) analysis of whether geographically targeted crime prevention efforts cause displacement to nearby, untargeted areas. To test this idea, two areas with high levels of street-level crime and disorder were subjected to increased police patrol, which is a way of increasing the risk of offending. Those areas as well as two neighboring areas were monitored during an experimental period to see whether offending in the target area "moved around the corner" to the neighboring areas. The researchers' quantitative results, which were based on systematic social observations of the areas, suggest that the increased policing did not displace crime from one area to the other, but rather reduced offending in both the targeted and nearby locales. Wisely, the researchers also included an ethnographic component in their investigation that entailed interviewing offenders. Among other findings, the qualitative data showed that some offenders chose a new method of crime commission rather than quit altogether or move elsewhere. For example, "[r]esearch subjects began prearranging dates by means of phone or beepers ...; quizzing potential clients to ensure they were not police officers; [and,] disguising their looks and engaging in stealthy 
solicitation" (Brisgone quoted in Weisburd et al., 2006, p. 581). These adaptations likely reduced the overall rate of offending because, one, they take extra time and, two, they are less obvious and therefore less likely to attract potential customers. Thus, the qualitative findings suggest that increased policing may have reduced offending not only by increasing its risk but also by increasing the effort involved.

Related to the above is a fourth way in which OBR can add to understanding of SCP: by finding out how offenders elude crime prevention efforts. From the perspective of control agents, the preferred result of implementing a SCP technique is that offenders choose to stop breaking the law or, if they persist, are incapacitated via institutionalization. The next best result is for persistent offenders to commit fewer offenses - a process known as restrictive deterrence (Gibbs, 1975; Jacobs, 1996). This commonly happens with drug dealers, as many of them choose to make fewer sales in exchange for diminished risk (Jacobs, 1999; Jacques \& Wright, 2015). For example, selling from known drug "hot spots" attracts drug buyers but also provokes attention from police; instead, then, some dealers legitimatize their presence by selling at places known for non-criminal activities, though this likely reduces their sales as well. St. Jean (2007) interviewed a Chicago dealer who explained how this tactic undercuts suspicions:

The corner stores, fast food joints, check cashing joints, and bus stops are all places where people be for a purpose. So how you going to tell me I have no reason to be there, or that I am here to sell dope. You don't know that. I may be here to wash my clothes, buy a bottle of water or something else from the corner store ... But I can only convince you about this if the businesses are there. So you see, this is why we hang out in these parts because ain't no telling exactly that you here to get or sell dope. (p. 124) 
An implication of such an illicit business practice is that police, business owners, and other stakeholders should work collaboratively to increase surveillance in these areas. St. Jean (2007) suggests bringing all stakeholders together, both formal and informal agents, to create a shared surveillance approach that would make "blending in" more difficult for offenders.

The fifth manner in which OBR can be used to shed light on SCP is by uncovering the unintended, negative consequences of particular techniques (see also Merton, 1936). Duneier's (1999) classic ethnography, Sidewalk, illustrates how policing measures intended to decrease crime may inadvertently increase some offense types. The technique in question is order maintenance policing (OMP). Based on broken windows theory (Kelling \& Wilson, 1982), OMP is geared toward preventing serious crimes like robbery and burglary by increasing the risks involved in minor crimes and disorderly conduct such as littering, loitering, panhandling, and fare evasion (see, e.g., Bratton, 1998). Though OMP has been found to substantially reduce serious crime (Zimring, 2011), it is by no means a perfect method of crime control. In addition to complaints that it is practiced in a discriminatory fashion (Gelman, Fagan, \& Kiss, 2007), another problem is that some efforts aimed at reducing specific offenses wind up increasing others. Based on observations of and interviews with unlicensed street vendors, Duneier (1999) shows how police officers' attempts to control this type of so-called disorder led to others. For instance, police would confiscate vendors' property if left unattended on the street, which was a way of increasing the risk of this quasi-legal business. This posed a serious dilemma to vendors when they needed to use the restroom, as they could not legally stay with their property and go to the bathroom at the same time. Instead of jeopardize losing their vending materials, venders opted to urinate in the street, albeit in a relatively secretive manner. Thus, police attempts to reduce one type of disorder, street vending, had the effect of increasing another, public urination. 
Such a finding suggests several practical implications: at the punitive end is increasing the risk of public urination, whereas "harm reduction" approaches include relaxing restrictions on time away from one's vending booth and putting a public lavatory nearby.

\section{Conducting OBR for the Sake of SCP}

As outlined and illustrated above, there are at least five ways in which OBR can inform understanding of SCP: (1) by directly determining what works to reduce crime; (2) generating findings that are suggestive of what prevention measures to invent and employ; (3) refining understanding of why a given prevention method reduces crime; (4) figuring out how offenders get around particular prevention measures; and, (5) gathering information on not only the positive but also the unintended, negative outcomes of prevention procedures. The first and second ways inform the extent to which SCP strategies and techniques reduce crime. The third and fourth lessons also do so, but their unique contribution is determining the exact mechanism behind a significant or null effect. And the fifth way of learning involves uncovering the consequences of SCP measures that are less visible until the offenders' perspective is taken into account. Thus, these five ways of learning not only garner knowledge of "what works" in reducing crime — a purely empirical question — but also illuminate the theoretical forces behind such effects, why some methods do not work, and the inadvertent but important problems that may result as well.

Returning to the point made in this chapter's introduction, OBR is uniquely able to shed light on these issues. To be clear, there is no doubt that data obtained from other sources, such as law enforcement officials and victims, can be used to inform crime prevention. However, if the analytic focus is crime (not "policing," "victimization," or whatnot), these other sources are more 
likely than OBR to result in indirect or incomplete information. For instance, police statistics are merely a proxy for crime because what they really measure is the amount of law enforcement (Black, 1970). And while victim statistics are useful for knowing the extent and nature of some crime types, like burglary and robbery, they are largely useless for victimless crimes, which include drug distribution and prostitution. What is more, offenders are better positioned than others to inform understanding of why and how they are affected by crime prevention measures. Police, victims, or other non-offenders may acquire that information somehow, but the source of that knowledge will always be an offender. There is no getting around it: research with criminals is the most direct route to information about crime, including how to prevent it.

For OBR to inform SCP, first OBR has to be conducted. In doing so, two major decision points always arise: What procedure should be used to sample offenders and should quantitative or qualitative data be obtained? Before closing, we provide some thoughts on the respective merits of the options, and also briefly discuss the limitations of OBR broadly.

The two major procedures of sampling offenders are via formal and informal channels. A formal channel is any government institution that houses or keeps a population list of (potential) offenders, such as a roster of persons in jail, prison, high school, or on parole or probation (see, e.g., Copes \& Vieraitis, 2012; Papachristos, Meares, \& Fagan, 2012). An informal channel is any route to offenders that does not involve relying on a government institution (see, e.g., Wright \& Decker, 1994, 1997). The formal and informal channels have opposite difficulties. The major difficulty associated with the formal channel is gaining permission of the "gatekeeper." By gatekeeper, we mean an individual who controls access to an institution and its members. If a gatekeeper's permission is not obtained, it is practically impossible to use the institution to facilitate research. With informal sampling, finding offenders and convincing them to participate 
is the major challenge because there is no population list to draw on. For that reason, a researcher who depends on informal sampling will often recruit offenders who also happen to be friends, family, coworkers or students, and from there build a snowball sample (see, e.g., Jacques \& Wright, 2008). The difficulty posed by this sampling procedure is that even the most well connected researcher will eventually exhaust his or her network of criminal ties. And for some researchers, such a network will be practically nonexistent to begin with and thereby preclude research getting off the ground. One way around this particular problem is for a researcher to tap into new networks, such as by going to a known drug hot spot and trying to recruit there (see, e.g., Jacobs, 1999). Yet that poses another problem, namely the chance of being victimized in the course of conducting research (Jacobs, 2006; Jacques \& Wright, 2010).

Whether a researcher uses a formal or informal channel to sample offenders is a crucial choice for some research questions. If the major goal of research is something like obtaining numbers generalizable to a particular population, clearly it is best to make use of available population lists. A researcher who uses an informal channel to recruit participants usually cannot make claims about statistical generalizability because, for one, the true population of offenders is unknown and, even if it was, informal sampling is rarely if ever truly random sampling (but see Copes et al., 2015). However, it will be better to use an informal sampling channel if the major goal of the research is more along the lines of "Why do some offenders not get arrested?" Obviously, it is not possible to study offenders who are yet to be arrested by sampling individuals who are in jail, prison, or listed on a parole or probation roster. These are just a couple examples meant to illustrate how the different channels of sampling offenders have different strengths and limitations (for further details, see Copes et al., 2015). If OBR is to reach its potential for informing SCP, both sampling channels should be used. 
Another important consideration for researchers is whether to use quantitative or qualitative methods. At the simplest level of conceptualization, quantitative research is based on numbers and qualitative research is not (Jacques, 2014). Analytically, a major difference between the two is that quantitative research can be used to produce statistical statements about the significance of effects, whereas qualitative research can only be used to create theoretically generalizable ideas (Small, 2006). Thus, quantitative research may often be the better option for determining what SCP techniques significantly reduce crime. However, the process that goes into conducting quantitative research often — though not necessarily—requires constraining a researcher's attention to a relatively narrow list of preconceived concerns; if this limitation is not self-imposed, the numbers can become distorted by such things as the ordering or wording of questions. Qualitative research, on the other hand, is relatively free from these constraints because the validity of findings is not a statistical matter. In other words, the limitation of qualitative research is also a virtue in that it allows for the introduction and discussion of previously unconsidered topics. Moreover, this freedom facilitates an expanded and more detailed collection of information. Answers are not boiled down to a number but rather are meant to be spelled out in detail: exactly why and how a crime was committed, for instance. Thus, qualitative research may be preferred when the goal is to refine understanding of why a given SCP method reduces crime, figuring out how offenders get around particular SCP measures, or gathering information on their unintended, negative consequences.

This paper has presented a sunny picture of OBR, but this method certainly has limitations (see Copes et al., in press; Bernasco, 2010). Perhaps the most widely circulated criticism is "Why should we believe what offenders tell us?" As Richard Wright puts it, we should expect offenders to lie for the very reason that they are offenders. In other words, people 
who break the law are untrustworthy. What is more, offenders may be motivated to distort the truth because revealing too much is risky. While there is likely some truth to such assertions, the same can often be said of victims, police, and other sources of criminological data. For example, victims may lie to gain justice, and police officers may lie to protect their colleagues. All of this is to say that offenders are not the only party with "good" reasons to tell less than the whole truth. Nonetheless, the lessons of OBR for SCP are brought into question to the extent that offenders are providing researchers with fiction.

In conclusion, we would like to emphasize that the five lessons of OBR for SCP should not be thought of as independent ventures, but rather as a curriculum. Each of the ways OBR contributes to knowledge of SCP is useful in its own right, but also because each lesson informs the totality. Whether, for example, a SCP technique is effective in reducing crime is important, but knowing the full utility of a technique also depends on knowing what, if anything, are its unintended, negative consequences. And figuring out how offenders circumvent particular SCP techniques may be used to improve or build the repertoire of effective methods available to control agents. In short, unlocking the full potential of OBR for informing SCP will require research geared toward all of its lessons. 


\section{References}

Bentham, J. (1789/1988). The principles of morals and legislation. Amherst, NY: Prometheus Books.

Bernasco, W. (Ed.). (2010). Offenders on offending: Learning about crime from criminals. Cullompton, UK: Willan Publishing.

Black, D. (1970). Production of crime rates. American Sociological Review, 35, 733-748.

Bratton, W. (1998). The Turnaround: How America's top cop reversed the crime epidemic. New York, NY: Random House.

Clarke, R. V. (2009). Situational crime prevention: Theoretical background and current practice. In M. D. Krohn, A. J. Lizotte, \& G. P. Hall (Eds.), Handbook on crime and deviance (pp. 259-276). New York, NY: Springer.

Clarke, R. V., \& Cornish, D. B. (1985). Modeling offenders' decisions: A framework for research and policy. Crime \& Justice, 16, 147-185.

Cohen, L., \& Felson, M. (1979). Social change and crime rate trends: A routine activity approach. American Sociological Review, 44, 588-608.

Copes, H., \& Cherbonneau, M. (2006). The key to auto theft: Emerging methods of auto theft from the offenders' perspective. British Journal of Criminology, 46, 917-934.

Copes, H., Jacques, S., Hochstetler, A., \& Dickinson, T. (2015). Interviewing offenders: The active vs. inmate debate. In H. Copes \& J. M. Miller (Eds.), Routledge handbook of qualitative criminology (pp. 157-172). London, UK: Routledge.

Copes, H., \& Vieraitis, L. M. (2012). Identity thieves: Motives and methods. Boston, MA: Northeastern University Press. 
Decker, S., Wright, R., \& Logie, R. (1993). Perceptual deterrence among active residential burglars: A research note. Criminology, 31, 135-147.

Duneier, M. (1999). Sidewalk. New York, NY: Farrar, Straus and Giroux.

Gelman, A., Fagan, J., \& Kiss, A. (2007). An analysis of the New York City Police Department's 'Stop-and-Frisk' policy in the context of claims of racial bias. Journal of the American Statistical Association, 102, 813-823.

Gibbs, J. P. (1975). Crime, punishment, and deterrence. New York, NY: Elsevier.

Hirschi, T. (1969). Causes of delinquency. Brunswick, NJ: Transaction Publishers.

Jacobs, B. (1996). Crack dealers and restrictive deterrence: Identifying narcs. Criminology, 34, 409-431.

Jacobs, B. (1999). Dealing crack. Boston, MA: Northeastern University Press.

Jacobs, B. (2006). The case for dangerous fieldwork. In D. Hobbs \& R. Wright (Eds.), The sage handbook of fieldwork (pp. 157-168). Thousand Oaks, CA: Sage Publications.

Jacques, S. (2014). The quantitative - qualitative divide in criminology: A theory of ideas' importance, attractiveness, and publication. Theoretical Criminology, 18, 317-334.

Jacques, S., \& Wright, R. (2008). Intimacy with outlaws: The role of relational distance in recruiting, paying, and interviewing underworld research participants. Journal of Research in Crime \& Delinquency, 45, 22-38.

Jacques, S., \& Wright, R. (2010). Dangerous intimacy: Toward a theory of violent victimization in active offender research. Journal of Criminal Justice Education, 21, 503-525.

Jacques, S., \& Wright, R. (2015). Code of the suburb: Inside the world of young middle-class drug dealers. Chicago, IL: University of Chicago Press. 
Kelling, G. L., \& Wilson, J. Q. (1982). Broken windows: The police and neighborhood safety. Atlantic Monthly, 249, 29-38.

Leclerc, B., Wortley, R., \& Smallbone, S. (2011). Victim resistance in child sexual abuse: A look into the efficacy of self-protection strategies based on the offender's experience. Journal of Interpersonal Violence, 26, 1868-1883.

Merton, R. K. (1936). The unanticipated consequences of purposive social action. American Sociological Review, 1, 894-904.

Papachristos, A. V., Meares, T. L., \& Fagan, J. (2012). Why do criminals obey the law? The influence of legitimacy and social networks on active gun offenders. Journal of Criminal Law \& Criminology, 102, 397-440.

Shaw, C. R. (1930). The jack-roller: A delinquent boy's own story. Chicago, IL: University of Chicago Press.

Small, M. L. (2006). 'How many cases do I need?' On science and the logic of case selection in field-based research. Ethnography, 10, 5-38.

St. Jean, P. K. B. (2007). Pockets of crime: Broken windows, collective efficacy, and the criminal point of view. Chicago, IL: University of Chicago Press.

Sutherland, E. H. (1937). The professional thief. Chicago, IL: University of Chicago Press.

Weisburd, D., Wyckoff, L. A., Ready, J., Eck, J. E., Hinkle, J. C., \& Gajewski, F. (2006). Does crime just move around the corner? A controlled study of spatial displacement and diffusion of crime control benefits. Criminology, 44, 549-592.

Wright, R., \& Decker, S. (1994). Burglars on the job: Streetlife and residential break-ins. Boston, MA: Northeastern University Press. 
Wright, R., \& Decker, S. (1997). Armed robbers in action: Stickups and street culture. Boston, MA: Northeastern University Press.

Zimring, F. E. (2011). The city that became safe: New York's lessons for urban crime and its control. New York, NY: Oxford University Press. 